\title{
Motor, Behavioral and Pharmacologic Findings in Tourette's Syndrome
}

\author{
Joseph Jankovic and Haydee Rohaidy
}

\begin{abstract}
We studied 112 patients with Tourette's syndrome (TS); the male-to-female ratio was 3.8, the mean age of onset was 7.3 years, and the average duration of symptoms prior to the initial evaluation was 15.2 years. Seventy-nine percent of the patients had at least one family member with motor or vocal tics, and an additional 10 percent had a family member with marked obsessive-compulsive behavior. Simple motor tics occurred as the presenting symptom in about one-third of patients; one-third had multiple motor tics at the onset, and another third started with vocal tics. During the course of the illness all patients developed multifocal motor tics and 86 percent had vocal tics. Verbal and mental coprolalia was present in 44 percent of the patients. Copropraxia was seen in 19 percent of patients, and both coprolalia and copropraxia were more frequent among the males than expected. Attentional deficit disorder was diagnosed in 36 percent of the patients and 32 percent had obsessive-compulsive personality. Sleep disturbances were reported by 62 percent of the patients and polysomnographs in 34 patients showed motor and vocal tics during all stages of sleep, sleep apnea, abnormal arousal pattern, and other sleep disturbances. Patients with mild symptoms improved with clonidine or clonazepam, but those with more advanced disorder required fluphenazine, pimozide, haloperidol or tetrabenazine.
\end{abstract}

RÉSUMÉ: Constations motrices, comportementales et pharmacologiques dans le syndrome de Gilles de la Tourette. Nous avons étudié 112 patients atteints du syndrome de Gilles de la Tourette; la proportion homme/femme était de 3.8, l'âge de début moyen était de 7.3 ans, et la durée moyenne des symptômes avant la première consultation était de 15.2 ans. Soixante-dix-neuf pourcent des patients avaient au moins un membre de leur famille qui présentait des tics moteurs ou vocaux et un autre dix pourcent avaient un membre de leur famille qui présentait un comportement obsessif-compulsif très marqué. Le symptôme de début était des tics moteurs simples chez le tiers des patients; un tiers avaient des tics moteurs multiples au début de leur maladie et chez l'autre tiers, la maladie avait commencé par des vocalisations. Au cours de leur maladie, tous les patients ont développé des tics moteurs multifocaux et 86 pourcent avaient des tics vocaux. La coprolalie verbale et mentale était présente chez 44 pourcent des patients. On a observé de la copropraxie chez 19 pourcent des patients, la coprolalie et la copropraxie étant plus fréquentes qu'on aurait été en droit de s'y attendre chez les sujets masculins. Trente-six pourcent des patients présentaient une incapacité de fixer leur attention et 32 pourcent avaient une personnalité obsessive-compulsive. Soixante-deux pourcent des patients ont rapporté qu'ils avaient des troubles du sommeil et des enregistrements polysomnographiques chez 34 patients ont montré des tics moteurs et vocaux pendant tous les stages du sommeil, de l'apnée du sommeil, un pattern d'éveil anormal, ainsi que d'autres troubles du sommeil. Les patients qui présentaient une symptômatologie peu sévère se sont améliorés avec la prise de clonidine ou de clonazepam; cependant, on a dû avoir recours à la fluphénazine, au pimozide, à l'halopéridol ou à la tétrabénazine chez ceux qui présentaient une symptômatologie plus sévère.

Can. J. Neurol. Sci. 1987; 14:541-546

In 1885 Georges Gilles de la Tourette described nine patients with motor tics. 'Other manifestations of the Gilles de la Tourette's syndrome (TS) included involuntary vocalizations seen in six patients, coprolalia in five, echolalia in five, and echopraxia in two. Two patients had other family members with tics. Since that time, many large series of TS have been reported..$^{2-6}$ However, most of the studies were based on a preselected population of patients seen either in a pediatric or a psychiatric clinic. Because of our interest in movement disorders, we have studied 112 consecutive patients with TS, both children and adults, with emphasis on motor manifestations.

\section{METHODS}

All patients were examined by one neurologist $(\mathrm{JJ})$. The motor and vocal tics were videotaped, and family members were questioned about other manifestations that were not evident during the clinic visit. Psychological evaluations and overnight polygraphic sleep studies were performed in 27 and 34 patients, respectively. The family history was obtained by detailed questioning of the spouse or parents, and whenever possible by examining the family members. All patients met the DSM III (Diagnostic and Statistical Manual of Mental Disorders, 3rd 
edition) criteria for TS, but we did not exclude patients if their onset was before 2 or after 15 years of age. The criteria for the diagnosis of TS are discussed further elsewhere. ${ }^{7}$ If the motor and behavioral manifestations were controlled with the current medication, then that medication was continued and was considered to be "the best medication. "If the symptoms were not satisfactorily controlled, the patients were treated with clonidine, clonazepam, fluphenazine, pimozide, haloperidol, or tetrabenazine, usually in that order. The response from each drug trial was rated according to the following scale: 1) excellent 2) moderate, or 3) poor control of motor and vocal tics. For a rating of 1 , the patient or his family members had to demonstrate not only a subjective improvement in the tics, but also an improvement in overall function, school or work performance, and an improvement in social interactions. The data was analyzed using the DBASE III plus program (Ashton-Tate).

\section{RESULTS}

One hundred and twelve patients were included in the study. The male-to-female ratio was 3.8 , the mean age at onset was 7.3 years (range: 1-28), and the average duration of symptoms prior to the initial evaluation was 15.2 years (range: $0-53$ ). There were eight patients who clearly had the onset of symptoms prior to age 2 and five with onset after age 15 . Seventy-nine percent of the patients had at least one family member with motor and vocal tics and additional 10 percent had relatives with marked obsessive-compulsive behavior. As expected, fathers, brothers, and sons were reported more frequently to be affected than the female members of the family (Table 1). Simple motor tic was the most frequent presenting symptom of TS, occurring in over a third of the patients at the onset of the disease. A third of the patients had multiple motor tics at the onset, and another third started with either simple or multiple vocal tics. Decreased attention span and learning difficulties occurred as initial symptoms in 8 percent of TS patients, and only 3 percent had coprolalia as the first manifestation of the disorder (Table 2).

During the course of the illness, all patients developed motor tics, usually involving the face and head region. Blinking was the most common motor tic, seen in more than half of all patients, followed by facial grimacing, head jerking, shoulder, arm and neck jerks, oculogyric deviations, tongue protrusion, and trunk and pelvic movements (Table 3). One-third of the patients had various movements of the shoulder varying from an occasional simple shrug to bizarre, dystonic, rotatory movements of the scapula. In addition to simple motor tics, many patients exhibited complex movements including hitting, kicking, whole body twisting, jumping, tapping, self-scratching, "stretching" or "cracking" of fingers, shaking of hands, compulsive touching, and other complex movements (Table 3). The most common vocal tic was throat clearing, occurring in about half of the patients, often prompting a referral to otolaryngologists; a third of the patients had sniffing which was often attributed to "allergies." Involuntary vocalizations also included grunting, humming, squeaking, coughing, barking, screaming, various expiratory sounds, whistling, snorting, blowing, and other noises (Table 4).

While often emphasized as a typical feature of TS, coprolalia was present in only 39 percent of the patients, although an additional five patients had mental coprolalia (obscene thoughts).
Table 1: Family Occurrence

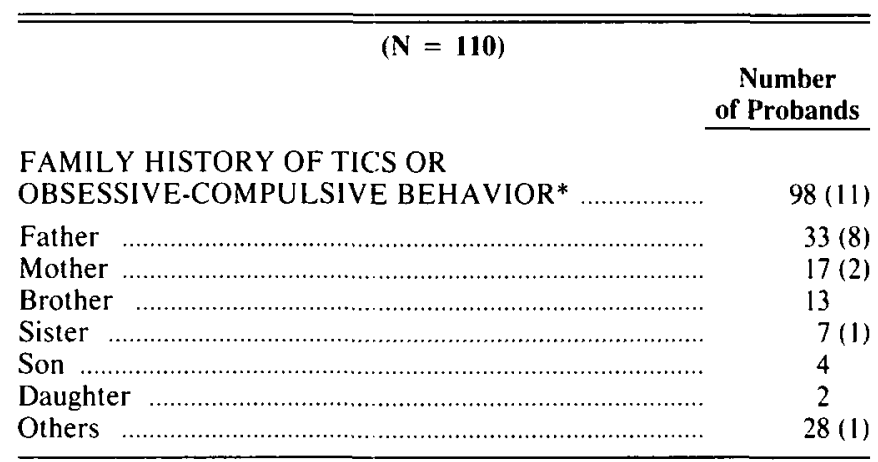

*( ) Obsessive-compulsive behavior

Table 2: Initial Symptoms

\begin{tabular}{|c|c|}
\hline$(\mathrm{N}=112)$ & $\begin{array}{c}\text { Number } \\
\text { of Patients }\end{array}$ \\
\hline Simple motor tics & 41 \\
\hline Multiple motor tics & 39 \\
\hline Simple vocal tics ... & 20 \\
\hline Multiple vocal tics ... & 15 \\
\hline Attention deficit or learning disability & \\
\hline Coprolatia & \\
\hline Echolalia & \\
\hline Echopraxia & 2 \\
\hline
\end{tabular}

Table 3: Motor Tics

$$
(\mathrm{N}=112)
$$

Number of Patients

FACE/HEAD

Blinking

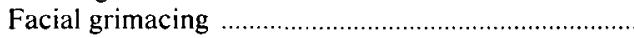

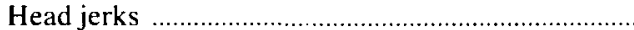

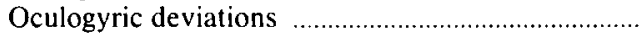

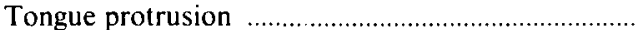

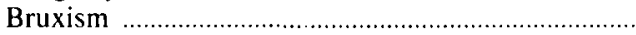

Blepharospasm

HEAD/SHOULDER

Shoulder jerks

Neck jerks

59

57

45

13

12

UPPER LIMBS

Arm jerks

Finger movements

TRUNK

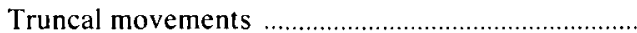

Pelvic thrusting

Abdominal jerks

11

LOWER LIMBS

Leg jerks

COMPLEX MOVEMENTS AND AGGRESSIVE

BEHAVIOR

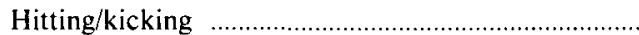

Whole body twisting ……………................................

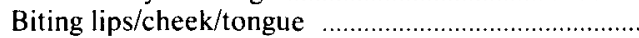

Jumping

"Cracking" fingers

Scratching self

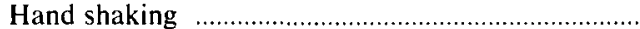

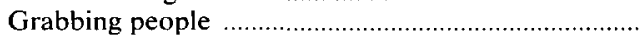

15
7
3
3
3
2


The male-to-female ratio of the patients with coprolalia was 4.4. The most common obscenities among the 43 patients with coprolalia were usually four-letter words describing sexual acts, ${ }^{18}$ body function or elimination acts, ${ }^{13}$ and organs of reproduction or sexual anatomy. ${ }^{7}$ The most common obscenities were "motherfucker," "fuck" and "shit," but many of these words were slurred and only parts of the words were actually pronounced. Profanities with a religious connotation were less common, occurring in only 4 patients. Animals such as "bitch," "bull" and "pig" were used by 6 patients. Copropraxia, an urge to make an obscene gesture, was seen in 19 percent of patients and the male-to-female ratio for this symptom was 20:1. Echolalia, repetition of words, or echopraxia, mimicking of gestures, was seen in less than one-third of the patients. Attentional deficit disorder was present in 36 percent of the patients and 32 percent had definite obsessive or compulsive personality traits. Many patients described various intrusive thoughts, internal fantasies, and compulsive ritualistic behavior. Self-destructive behavior occurred in 9 percent of the patients and ranged from biting nails to more harsh self-mutilating acts: six patients had bitten their lips, cheek, or tongue, and two scratched themselves to the point of bleeding (Table 5). One patient with congenitally narrowed cervical spinal canal became quadriplegic because of violent uncontrollable neck tics.

Sleep disturbances were reported by 62 percent of patients (Table 6). Enuresis sometimes persisted until the age of 13 years. Twenty-two patients were observed by their parents or their spouse to have motor or vocal tics during sleep. Sleep recordings were performed in 34 patients and showed motor tics during all stages of sleep in 23, reduced REM sleep in 18 , abnormal arousal pattern in 10, and sleep apnea in 8 (Table 6).

Most patients required a trial of more than one medication before a satisfactory improvement could be achieved (Table 7). Clonidine and clonazepam were tolerated relatively well except for mild side effects such as drowsiness, fatigability, depression, and anxiety; one patient treated with clonazepam had a rash. However, only a third of the patients treated with either drug had an excellent response. Pimozide, fluphenazine, and tetrabenazine seemed most effective, about half of the patients achieving excellent response, but these medications were also associated with more adverse reactions. About a third of the patients experienced sedation, weight gain, depression, acute dystonic reaction or parkinsonian features. Haloperidol had the highest incidence of these adverse reactions. There were no electrocardiogram abnormalities attributable to pimozide.

\section{Discussion}

TS is among the most frequently misdiagnosed neurologic disorders; therefore the true prevalence is unknown. However, the prevalence has been estimated at 0.05 percent. ${ }^{8}$ One of the chief reasons for the difficulties in diagnosing TS is the failure to appreciate the full spectrum of the phenomenology of tics. ${ }^{7}$ Motor tics consist of involuntary, abrupt, brief, coordinated muscle contractions. Tics can occur as isolated simple events such as eye blinking, facial grimacing, head twitching, or shoulder shrugging. About 51 percent of Shapiro's ${ }^{3}$ patients began with a simple tic in a single location, whereas 37 percent of our patients had a simple tic as the presenting symptom (Table 2 ). Multiple tics were present at onset in 49 percent of Shapiro's ${ }^{3}$ patients and in 35 percent of our patients. Only 19 percent of the
TS patients in the Shapiro's ${ }^{3}$ series had vocalizations at their onset, whereas 31 percent of our patients started with vocal tics. During the course of the illness 83 percent of Shapiro's ${ }^{3}$ patients had eye blinking, 79 percent had head jerking. 65 percent had shoulder shrugs, 60 percent arm jerks, and 52 percent had neck tics. The corresponding percentages for our

Table 4: Vocal Tics and Noises

\begin{tabular}{|c|c|}
\hline$(N=112)$ & $\begin{array}{c}\begin{array}{c}\text { Number } \\
\text { of Patients }\end{array} \\
\end{array}$ \\
\hline Throat clearing & 53 \\
\hline 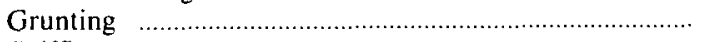 & 45 \\
\hline Sniffing & 39 \\
\hline Humming …................................ & 26 \\
\hline 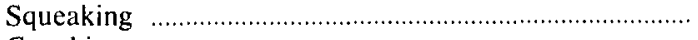 & 24 \\
\hline 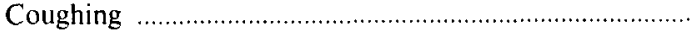 & 18 \\
\hline Barking & 16 \\
\hline 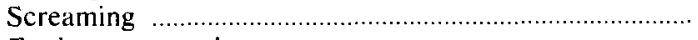 & 11 \\
\hline Expiratory sounds & \\
\hline 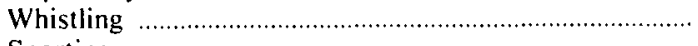 & \\
\hline 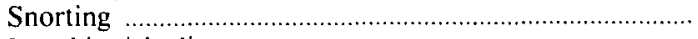 & \\
\hline Laughing/giggling & \\
\hline 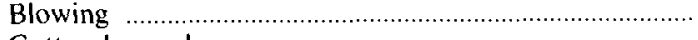 & \\
\hline Guttural sounds & \\
\hline Hyperventilating & \\
\hline Sucking & \\
\hline Spitting & \\
\hline Growling & \\
\hline Other sounds & \\
\hline \multicolumn{2}{|l|}{ Table 5: Associated Symptoms } \\
\hline$(N=112)$ & \\
\hline & $\begin{array}{c}\text { Number } \\
\text { of Patients }\end{array}$ \\
\hline Coprolalia & 43 \\
\hline Attentional deficit disorder & 40 \\
\hline Obsessive compulsive trait & 36 \\
\hline 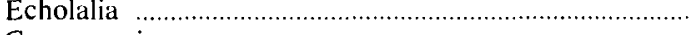 & 30 \\
\hline Copropraxia & 21 \\
\hline 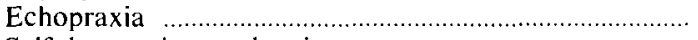 & 12 \\
\hline Self-destructive tendencies & 10 \\
\hline 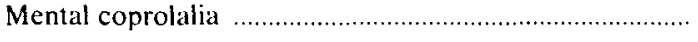 & \\
\hline
\end{tabular}

Table 6: Sleep Disturbances

$(\mathrm{N}=112)$

Number of Patients

SLEEP COMPLAINTS

Tics during sleep ……………………………….......

Enuresis

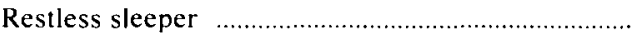

Insomnia .................................................

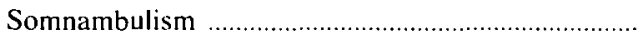

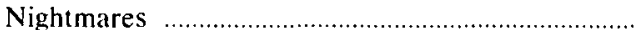

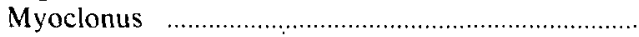

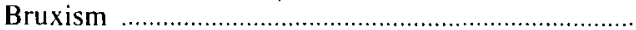

POLYSOMNOGRAPHIC STUDIES

Motor tics

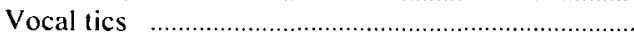

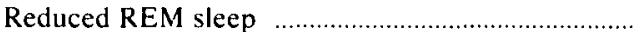

Abnormal arousals ........................................................

Apnea (obstructive) 
patients were $53,40,34,19$, and 16 percent. We cannot explain the difference between the two series, but it is possible that our patients were less severely affected than those in the Shapiro's ${ }^{3}$ series. We did not insist on age of onset between 2 and 15 because some patients clearly had their onset out of this range. We also did not insist on multiple motor and verbal tics to be present in each patient because some patients with otherwise typical TS or with typical TS in a family member, have only simple motor or vocal tics when first seen and later developed into the full syndrome. Finally, we did not require that "symptoms always disappear during sleep and orgasm." later, tics often persist during sleep, although they markedly diminish during sleep and when patients are engaged in sexual activity.

Besides simple or multifocal jerks, tics can also manifest themselves as bursts or sequences of patterned, coordinated, complex movements such as jumping, hitting, touching, tapping, shaking of hands and kissing. Simple or complex tics are sometimes mistaken for voluntary movements. However, the absence of pre-movement cortical potential before a tic suggests that the movement originates in some subcortical structures and, therefore, is not volitional. ${ }^{9}$ Some patients, nevertheless, perceive their tics as being intentional because they "satisfy" certain sensations, urges, and compulsions. ${ }^{10.11}$ This sensory component helps to differentiate tics from other hyperkinetic movement disorders, such as tremor, chorea, athetosis, ballism, dystonia, myoclonus and focal seizures. Tics fluctuate in response to the emotional state of the patient, increasing with stress, and they may be suppressed volitionally, at least for a few minutes. The suppressibility is another feature that helps to differentiate tics from the other movement disorders.

While most patients with TS have brief, unsustained, repetitive muscle contractions (clonic tics), about one-third also have more sustained, tonic contractions (dystonic tics). The dystonic tics may occur as blepharospasm and oculogyric deviations, ${ }^{12.13}$ or as dystonic movements of the neck, shoulders and trunk. ${ }^{7}$

Another feature that helps distinguishing tics from the other hyperkinetic movement disorders is the observation that tics may occur during all stages of sleep. ${ }^{14}$ Polysomnographic recordings in 34 patients showed motor tics in 23 and vocal tics in 4

Table 7: Response to Medications

\begin{tabular}{cccc}
\hline DRUG & \multicolumn{3}{c}{ Response } \\
\hline $\begin{array}{c}\text { Haloperidol } \\
(\mathrm{n}=34)\end{array}$ & 11 & $\mathbf{2}$ & $\mathbf{3}$ \\
\hline $\begin{array}{c}\text { Fuphenazine } \\
(\mathrm{n}=28)\end{array}$ & $(32 \%)$ & $(56 \%)$ & $(12 \%)$ \\
Clonidine & 15 & 9 & 4 \\
$(\mathrm{n}=27)$ & $(54 \%)$ & $(32 \%)$ & $(14 \%)$ \\
Tetrabenazine & 9 & 9 & 9 \\
$(\mathrm{n}=15)$ & $(33 \%)$ & $(33 \%)$ & $(33 \%)$ \\
Clonazepam & 7 & 5 & 3 \\
$(\mathrm{n}=13)$ & $(47 \%)$ & $(33 \%)$ & $(20 \%)$ \\
Pimozide & 5 & 5 & 3 \\
$(\mathrm{n}=9)$ & $(38 \%)$ & $(38 \%)$ & $(24 \%)$ \\
& 5 & 2 & 2 \\
\hline
\end{tabular}

RATING SCALE 1. Excellent response

2. Moderate response

3. Poor response occurring during all stages of sleep. The tics recorded during sleep are similar to those observed during wakefulness. Other disturbed sleep patterns include sleep apnea, enuresis, insomnia, abnormal sleep arousal patterns, nightmares and somnambulism. In one survey of 59 TS patients, 76 percent had sleep disturbance compared to 35 percent of age and sex-matched controls $\left(X^{2}=p 0.00001\right) .^{15}$ These sleep disturbances seem to be particularly common in patients with a family history of TS or tics. ${ }^{4.14}$

The origin of TS is believed by some to be psychiatric or emotional, but the clinical, physiological and biochemical findings have provided a strong support for a basis in neural dysfunction (organic). ${ }^{16}$ However, behavioral disturbances frequently accompany the motor and vocal tics. Among the behavioral disorders, the obsessive-compulsive symptoms are the most prominent, ${ }^{17}$ seen in 32 percent of our patients. The percentage of TS patients with an obsessive-compulsive disorder varies between 12 and 74 percent, depending on the diagnostic criteria and other methodologic variables. ${ }^{18}$ Some studies have provided evidence for a genetic linkage between TS and the obsessivecompulsive disorder. ${ }^{18}$ In contrast, attentional deficit disorder with hyperactivity, seen in 36 percent of our patients, does not seem genetically related to TS. ${ }^{19}$ We have noted unusual musical and athletic talents in some of our patients.

Vocal disturbances in TS patients range from various involuntary noises and sounds to echolalia, palilalia, and stuttering. In our series, throat clearing, grunting, sniffing, humming, squealing, coughing, barking and screaming were the most common vocalizations. Coprolalia may simply represent a linguistic equivalent of a vocal tic. ${ }^{20}$ The frequency of coprolalia in patients with TS has ranged from $8 \%$ to $64 \% .^{3,6}$ Verbal coprolalia was seen in 38 percent of our patients while mental coprolalia was reported by only 5 percent. Among Shapiro's ${ }^{3}$ patients 56 percent spoke coprolalic words and 8 percent only thought of obscene words. Similar to other studies our data indicate that coprolalia increases with age, but may spontaneously disappear several years later. Words with sexual connotation were used much more frequently than religious profanities. This pattern is also seen in other languages and in other countries, reflecting a strong cultural inhibition of such obscenities (Table 8). ${ }^{21}$

A genetic predisposition was already suggested by Gilles de la Tourette and confirmed by later studies. ${ }^{1,22.23}$ Eighty-nine percent of our patients had a first degree relative with tics, TS, or obsessive-compulsive behavior ( 10 percent). This familial frequency is probably an underestimation because not all family members have been examined. The mode of inheritance is unknown. However, a highly penetrant, sex-influenced, autosomal dominant trait or a major semidominant gene with variable penetrance have been proposed. ${ }^{23.24}$ Twin studies have shown higher concordance rates in monozygotic twins when compared to dizygotic twins. ${ }^{25,26}$ However, nongenetic factors must account for the fact that not all monozygotic twins are fully concordant and that even when a twin pair is affected, there is a marked phenotypic heterogeneity. ${ }^{25}$ A Tourette family was recently identified with all six affected members having 7q22: 18q22 balanced translocation. ${ }^{27} \mathrm{We}$ found an occasional coexistence between TS and other genetic disorders such as phenylketonuria, neurofibromatosis, congenital myopathy and others. While such associations may be purely coincidental they may provide clues to the genetic mechanisms of TS.

The management of TS is based upon the severity of the symptoms and the impact on school or job performances, fam- 
ily and peer interrelationships and on other aspects of normal psychosocial interactions. ${ }^{28}$ Many patients do not need medications because their symptoms are not disabling. Before initiating pharmacologic therapy the diagnosis should be clearly established. Secondary tic disorders due to anti-psychotic drugs, anticonvulsants, central stimulants, dopaminergic drugs, carbon monoxide intoxication, head trauma and encephalitis should be excluded. ${ }^{16.29}$ Blood smear should be examined for evidence of neuroacanthocytosis which is characterized by a variety of findings including motor and vocal tics, lip-biting, chorea, dystonia, parkinsonism, areflexia, amyotrophy, seizures and elevated CK levels. ${ }^{30}$

Based on some indirect evidence from clinical pharmacologic studies, including an improvement of TS symptoms with dopamine blocking or depleting agents, an exacerbation with central stimulants and with dopaminergic drugs, and a low CSF homovanillic acid in some patients, it has been proposed that the underlying mechanism for TS involves "supersensitive" dopamine receptors. ${ }^{31-33}$ However, recent PET scan and postmortem receptor ligand studies have not confirmed this hypothesis. ${ }^{34}$ The meaning of low dynorphin found in the striatal system projecting to the pallidum in one autopsied brain is still unclear. ${ }^{35}$ The other neuropeptides seem to be present in normal concentrations.

Haloperidol, first tried for TS in 1961, is probably the most frequently used drug in the treatment of TS. ${ }^{36,37}$ Although a satisfactory improvement can be achieved with haloperidol in about two-thirds of patients, less than a third can continue the drug for an extended period of time.$^{37}$ Even when the drug is increased slowly $(0.5 \mathrm{mg} /$ week $)$ about a third of the patients experience such problems as irritability, depression, lassitude, loss of motivation, mental dullness, hypersomnia, parkinsonian symptoms, akathisia and weight gain. We have not observed serious allergic reactions, hepatotoxicity, or agranulocytosis, but these adverse reactions may also occur with haloperidol. We, and others, ${ }^{38.39}$ have observed tardive dyskinesia, in some cases permanent, in Tourette's patients treated with haloperidol and with other dopamine receptor blocking agents. Tardive dyskinesia may be difficult to detect in patients with facial tics and may partly account for the low incidence of this complication reported in the literature. ${ }^{37.40}$

We use fluphenazine (1,42 $^{\text {or pimozide }}{ }^{43,44}$ if dopamine blocking drugs are needed to control disabling symptoms. Fluphenazine, a piperazine phenothiazine, seems to have an efficacy superior to haloperidol (Table 7) and has a lower incidence of sedation. Pimozide, a diphenylbutyl piperidine derivative, also seems to be more effective than haloperidol and has fewer adverse effects. While monitoring for potential cardiotoxicity has been recommended, none of our patients have had any ECG changes during the pimozide therapy.

Tetrabenazine, a benzoquinoline derivative which depletes monoamines and blocks presynaptic and postsynaptic dopamine receptors has also been studied in TS. ${ }^{45}$ Despite some side effects, including drowsiness, depression, irritability and parkinsonism, about eighty percent of the patients show a marked or moderate improvement in the intensity and frequency of their tics with tetrabenazine.

Clonidine, an imidazoline derivative, has a central agonist effect on the presynaptic alpha2-adrenergic receptors, thereby reducing noradrenaline turnover ${ }^{46}$ Plasma free levels of methoxyhydroxy-phenylethylene glycol (MHPG), a metabolite of norepinephrine, are reduced in TS patients who improve with clonidine. ${ }^{47}$ Some patients feel "calmer" after a few days of taking clonidine and often notice an improvement in their behavioral problems. ${ }^{48}$ Clonazepam may have a similar behavioral effect. $^{49}$

Although our study is retrospective and open label, it provides some insight into the differential efficacy of the various drugs (Table 7). Fifty-six percent of patients treated with pimozide achieved "excellent" response, but the number of patients was small $(\mathrm{N}=9)$. Second most effective drug was fluphenazine, with 54 percent of the 28 treated patients having "excellent" response. Tetrabenazine produced "excellent" result in 47 percent of the 15 patients. Since tetrabenazine was used as the last drug, after all the other drugs failed to control the symptoms, our results may be somewhat biased against this drug. Clonazepam produced "excellent" improvement in 38 percent of 13 patients, clonidine in 33 percent of 27 and haloperidol in 32 percent of the 34 treated patients. In some patients refractory to single medications, a combination of pimozide or fluphenazine with tetrabenazine seemed particularly helpful.

Although recognized over a 100 years ago, the greatest advances in the understanding of TS and its clinical, behavioral, genetic and neurochemical complexities have been achieved only in the last two decades. ${ }^{50} \mathrm{~A}$ combined pharmacotherapeutic ${ }^{28}$ and behavioral approach ${ }^{51}$ should improve the functioning of most, if not all, patients with TS.

\section{ACKNOWLEDGEMENT}

We thank Janet Orman, R.N. for her assistance in the collection of the data.

\begin{tabular}{lllll}
\hline \multicolumn{2}{l}{ Table 8: Coprolalia in Patients with TS in the United States and in Three European Countries } \\
\hline \hline USA (PRESENT) & USA (3) & ENGLAND (21) & DENMARK (21) & SPAIN (21) \\
\hline Mother-fucker & Fuck & Fuck & Fisse (vulva) & Puta (whore) \\
Fuck(er,-off) & Shit & Cunt & Kusse (vulva) & Mierda (shit) \\
Shit & Cunt & Bastard & Kaeft (shut-up) & Coño (cunt) \\
Bitch & Mother-fucker & Piss & Pik (prick) & Joder (fuck) \\
Pussy & Prick, dick & Sod & Rov (arse) & Maricon (queer) \\
Asshole & Cocksucker & Cock & Gylle (animal shit) & Cojones (balls) \\
& Nigger & Shit & & Hijo de puta (son of a whore) \\
& Bull & Prick & & Hostia (holy bread) \\
& Damn & Wank & & Cabron \\
& & & Jillipolla \\
\hline
\end{tabular}




\section{REFERENCES}

I. Gilles de la Tourette G. Etude sur une affection nerveuse caracterisée par de l'incoordination motrice accompagnée d'écholalie et de coprolalie. Archives de Neurologie 1985: 9: 19-24, 153-156.

2. Moldofsky H, Tullis C. Lamon R. Multiple tic syndrome (Gilles de la Tourette's syndrome). J Nerv Ment Dis 1974: 159: 282-291.

3. Shapiro AK, Shapiro ES. Bruun RD. Sweet RD. Gilles de la Tourette syndrome. New York. Raven Press 1978, pp 119-149.

4. Nee LE, Caine ED. Polinsky RJ, et al. Gilles de la Tourette syndrome: Clinical and family study of 50 cases. Ann Neurol 1980: 7: 41-49.

5. Lees AJ, Robertson M, Trimble MR, Murray NMF. A clinical study of Gilles de la Tourette syndrome in the United Kingdom. J Neurol. Neurosurg Psychiatry 1984; 47: 1-8.

6. Erenberg G. Cruse RP. Rothner AD. Tourette syndrome: an analysis of 200 pediatric and adolescent cases. Cleve Clin Q 1986:53: 127-131.

7. Jankovic J, Fahn S. The phenomenology of tics. Movement Disorders 1986: 1: 17-26.

8. Shapiro AK, Shapiro E. Tourette syndrome. History and present state. In: Friedhoff AJ. Chase TN (eds) Gilles de la Tourette Syndrome. Adv Neurol. Raven Press, New York, 1982; Vol 35. pp 17-23.

9. Obeso JA. Rothwell JC. Marsden CD. Simple tics in Gilles de la Tourette's syndrome are not prefaced by a normal premovement EEG potential. J Neurol Neurosurg Psychiatry 1981:44: 735-738.

10. Bliss J. Sensory experiences of Gilles de la Tourette's syndrome Arch Gen Psychiatry 1980: 37: 1343-1347.

11. Bullen JG, Hemsley DR. Sensory experience as a trigger in Gilles de la Tourette's syndrome. J Behav Ther Exp Psychiatry 1983: 14: 197.201.

12. Jankovic J. Clinical features. differential diagnosis and pathogenesis of blepharospasm and cranial-cervical dystonia. $l n$ : Bosniak SL (ed) Blepharospam. New York. 1985. pp 67-82.

13. Frankel $\mathbf{M}$, Cummings JL. Neuro-opthalmic abnormalities in Tourette's syndrome: Functional and anatomic implications. Neurology 1984: 34: 359-361

14. Glaze DG, Frost JD, Jankovic J. Gilles de la Tourette's syndrome. Disorder of arousal. Neurology 1983: 33: 586-592.

15. Kovacevic-Ristanovic R, Goetz CG, Tanner CM, Gilley D. Gilles de la Tourette's syndrome and sleep. Neurology 1987 (in press).

16. Jankovic J. The neurology of tics. In: Fahn $S$, Marsden $C D$, eds Movement Disorders 2. Butterworth Scientific 1987; 383-405.

17. Frankel M. Cummings JL, Robertson MM, et al. Obsessions and compulsions in Gilles de la Tourette's syndrome. Neurology 1986: 36: 378-382.

18. Pauls DL, Towbin KE, Leckman JF, et al. Gilles de la Tourette's syndrome and obsessive-compulsive disorder. Evidence supporting a genetic relationship. Arch Gen Psychiatry 1986; 43: 1180-1182.

19. Pauls DL. Hurst CR. Kruger SD, et al. Gilles de la Tourette's syndrome and attention deficit disorder with hyperactivity. Evidence against a genetic relationship. Arch Gen Psychiatry 1986: 43: $1177-1179$.

20. Nuwer MR. Coprolalia as an organic symptom. In: Gilles de la Tourette syndrome. Friedhoff AJ. Chase TN, eds. Adv Neurol, Raven Press, New York 1982: 35: 363-368.

21. Lees AJ. Tolosa E. Tics. In: Jankovic J. Tolosa E. eds. Parkinson's disease and movement disorders, Urban and Schwarzenberger Baltimore. Maryland. 1987. in press.

22. Pollack MA. Cohen NL, Friedhoff AJ. Gilles de la Tourette syndrome: Familial occurrence and precipitation by methylphenidate therapy. Arch Neurol 1977: 34: 630-632.

23. Kurlan R, Behr J, Medved L, et al. Familial Tourette syndrome: Report of a large pedigree and potential for linkage analysis. Neurology 1986; 36: 772-776.

24. Pauls DL. Leckman JF. The inheritance of Gilles de la Tourette's syndrome and associated behaviors. Evidence for autosomal dominant transmission. N Engl J Med 1986: 315: 993-997.

25. Waserman J, Lal S, Gauthier S. Gilles de la Tourette's syndrome in monozygotic twins. J Neurol Neurosurg Psychiatry 1983: 46: 75-77.

26. Price A, Kidd K. Cohen D, et al. A twin study of Tourette syndrome Arch Gen Psychiatry 1985; 42: 815-820.
27. Comings DE, Comings BG, Dietz G, et al. Evidence the Tourette syndrome gene is at $18 \mathrm{q}: 22.1$. 7th International Congress of Human genetics, Berlin, 1986 abstract 11: 620 .

28. Jankovic J. Recent advances in the management of tics. Clin Neuropharmacol 1986 (Suppl 2); S100-S110.

29. Erenberg G. Gruse RP. Rothner DA. Gilles de la Tourette's syndrome. Effects of stimulant drugs. Neurology 1985; 35: 1346-1348.

30. Spitz MC, Jankovic J. Killian JM. Familial tic disorder, parkinsonism. motor neuron disease, and acanthocytosis - a new syndrome. Neurology 1985; 35: 366-377.

31. Koslow SH, Cross CK. Cerebrospinal fluid monoamine metabolites in Tourette syndrome and their neuroendocrine implications. In: Gilles de la Tourette syndrome. Friedhoff AJ, Chase TN, eds. Adv Neurol 1982: 35: 185-197.

32. Cohen DJ, Shaywitz BA, Young JG. et al. Central biogenic amine metabolism in children with the syndrome of chronic multiple tics of Gilles de la Tourette: Norepinephrine, serotonin and dopamine. J Am Acad Child Psychiatry 1979; 18: 320-341.

33. Butler IJ. Tourette's syndrome. Some new concepts. In: Movement Disorders. J Jankovic, ed. Neurol Clin 1984:2: $571-580$.

34. Singer HS, Wong DF, Tiemeyer M, et al. Pathophysiology of Tourette syndrome. A PET and postmortem analysis. Ann Neurol 1985; 18: 446.

35. Haber SN. Kowell NW. Vonsattel JP. et al. Lack of dynorphin. but no enkephalin or substance $P$. immunoreactivity in the dorsal globus pallidus in Gilles de la Tourette`s syndrome. J Neurol Sci 1986: 75: 225-241.

36. Seignot MJN. A case of the syndrome of tics of Gilles de la Tourette controlled by R1625. Am Med Psychol 1961: 1 19: 578-579.

37. Shapiro AK, Shapiro E. The treatment and etiology of tics and Tourette syndrome. Compr Psychiatry 1981: 22: 193-205.

38. Mizrahi EM, Holtzman D, Tharp B. Haloperidol-induced tardive dyskinesia in a child with Gilles de la Tourette's syndrome. Arch Neurol 1980; 37: 780 .

39. Golden GS. Tardive dyskinesia in Tourette's syndrome. Ann Neurol 1984: 16: 390

40. Jankovic J. Cranial-cervical dyskinesias. In: Appel SH. ed. Current Neurology, Year Book Medical Publishers, Chicago, 1986, Vol 6, pp 153-176.

41. Goetz CG, Tanner CM, Klawans HL. Fluphenazine and multifocal tic disorders. Arch Neurol 1984: 41: 271-272.

42. Borison RL, Ang L, Change S, et al. New pharmacological approaches in the treatment of Tourette syndrome. In: Gilles de la Tourette Syndrome. (Eds.) Friedhoff AJ, Chase TN. Adv Neurol New York, Raven Press 1982; Vol 35, pp 377-382.

43. Shapiro AK, Shapiro E. Controlled study of pimozide vs. placebo in Tourette's syndrome. J Am Acad Child Psychiatry 1984; 23: 161-173.

44. Regeur L, Pakkenberg B, Fog G, Pakkenberg H. Clinical features and long-term treatment with pimozide in 65 patients with Gilles de la Tourette's syndrome. J Neurol Neurosurg Psychiatry 1986: 49: 791-795.

45. Jankovic J, Glaze DG, Frost JD. Effect of tetrabenazine on tics and sleep of Gilles de la Tourette's syndrome. Neurology 1984: 34: 688-692.

46. Svensson TH, Bunney BS, Aghajanian GK. Inhibition of both noradrenergic and serotonergic neurons in brain by the alphaadrenergic agonist clonidine. Brain Res 1975; 92: 291-306.

47. Young JG, Cohen DJ, Hattox SE. Plasma free MHPG and neuroendocrine responses to challenge doses of clonidine in Tourette's syndrome: Preliminary report. Life Sci 1981: 29: 1467-1475.

48. Leckman JF, Detlor J, Harcherick DF, et al. Short and long term treatment of Tourette's syndrome with clonidine: A clinical perspective. Neurology 1985: 35: 343-351.

49. Gonce M, Barbeau A. Seven cases of Gilles de la Tourette's syndrome: Partial relief with clonazepam: A pilot study. Can J Neurol Sci 1977: 4: 279-283.

50. Caine ED. Gilles de la Tourette's syndrome. A review of clinical and research studies and consideration of future directions for investigation. Arch Neurol 1985: 42: 393-397.

51. Mansdorf 1 . Assertiveness training in the treatment of a child's tics. J Behav Ther Exp Psychiatry 1986: 17: 29-32. 